Research Paper

\title{
Stromal Infiltration of Tumor-Associated Macrophages Conferring Poor Prognosis of Patients with Basal-Like Breast Carcinoma
}

\author{
Mu Yang1, 2, Zhenhua Li1, Meijing Ren¹, Shuai Li1, Lanjing Zhang2,3,4,5, Xinmin Zhang, Fangfang Liu1 ${ }^{\circledR}$ \\ 1. Department of Breast Pathology and Research Laboratory, Key Laboratory of Breast Cancer Prevention and Therapy (Ministry of Education), National \\ Clinical Research Center for Cancer, Tianjin Medical University Cancer Institute and Hospital, Tianjin 300060, China \\ 2. Department of Pathology, University Medical Center of Princeton, Plainsboro, NJ 08854, USA \\ 3. Rutgers Cancer Institute of New Jersey, New Brunswick, New Jersey, USA; \\ 4. Department of Biological Sciences, Rutgers University, Newark, New Jersey, USA; \\ 5. Department of Chemical Biology, Ernest Mario School of Pharmacy, Rutgers University, Piscataway, New Jersey, USA \\ 6. Department of Pathology, Cooper University Hospital, Cooper Medical School of Rowan University, Camden, New Jersey 08103, USA
}

$\square$ Corresponding author: Fangfang Liu, MD, PhD, Department of Breast Pathology and Research Lab, Tianjin Medical University Cancer Institute and Hospital, Huanhuxi Road, Tianjin 300060, China. Tel: 86-22-23340123; Fax: 86-22-23340123; Email: pengzhiryn@mail.nankai.edu.cn

(C) Ivyspring International Publisher. This is an open access article distributed under the terms of the Creative Commons Attribution (CC BY-NC) license (https://creativecommons.org/licenses/by-nc/4.0/). See http://ivyspring.com/terms for full terms and conditions.

Received: 2018.01.25; Accepted: 2018.03.30; Published: 2018.06.06

\begin{abstract}
Aims: Tumor associated macrophages (TAMs) play a critical role in the initiation and progression of breast cancer. However, their prognostic significance in the molecular subtype of basal-like breast cancer (BLBC) is poorly understood. The aim of this study was to investigate the extent and patterns of TAMs in BLBC and their associations with clinicopathological features and patient survival.

Methods and Results: We evaluated TAMs in 200 cases of BLBC by immunohistochemistry using the M2 macrophage marker CD163 and the pan-macrophage marker CD68 in tumor nest and stroma, and assessed their prognostic significance.

The study demonstrated that infiltration of $\mathrm{CD}_{163^{+}}$and $\mathrm{CD} 68^{+}$macrophages in tumor stroma was of clinical relevance in BLBC, but not those in tumor nest. Increased stromal infiltration of CD68 ${ }^{+}$or $\mathrm{CD} 63^{+}$macrophages correlated with larger tumor size, higher histological grade, higher 5-year recurrence and 5-year breast cancer mortality. Although both of $\mathrm{CD}^{2} 8^{+}$and $\mathrm{CD} 163^{+}$macrophages in tumor stroma were associated with poor recurrence-free survival (RFS) and overall survival (OS), multivariate analysis demonstrated that only $\mathrm{CD}_{163^{+}}$macrophage was an independent predictor of RFS and OS.

Conclusions: Our results highlight the prognostic importance of TAMs' location in BLBC. CD163, a highly specific biomarker for $\mathrm{M} 2$ macrophages, is an independent prognostic marker for BLBC patients, and may serve as an indicator or potential target of macrophage-centred therapeutic strategies.
\end{abstract}

Key words: Tumor associated macrophages, CD163, CD68, Basal-like breast cancer, Prognosis

\section{Introduction}

Inflammatory cells are a key component of the tumor microenvironment and influence the growth and progression of tumor [1,2]. Tumor-associated macrophages (TAMs) constitute a major component of leukocyte population infiltrating tumors of the breast $[3,4]$. Numerous studies have demonstrated that TAMs enhance tumor invasion, migration and angiogenesis in many solid tumors including breast cancer [5-7], however, with the deepening of the research, controversial conclusions have always been made. 
Accumulating evidences suggests that macrophages are not a homogenous population. Thus, it should be more prudent to get a conclusion in the relationship between TAMs heterogeneity and breast cancer heterogeneity. Breast cancer is one of the few types of tumor that molecular classification has been successfully used in individualized treatment design, which can significantly improve disease specific patient survival [8]. Triple-negative breast cancer is negative for hormone receptors (HR) of estrogen (ER) and progesterone (PR), and human epidermal growth factor receptor-2 (HER2), and thus cannot benefit from the targeted treatment, such as Tamoxifen, Anastrozole, and Trastuzumab [9, 10]. A number of independent studies have demonstrated the correlation of TAM with ER-negativity, PR-negativity, and high mitotic rate [11-20]. Medrek C et al. found intensity of macrophage infiltration in tumor stoma inversely correlated with luminal A phenotype and positively correlated with triple-negative/basal-like phenotype of breast cancer [20]. We noticed that the association of TAMs with poor outcome was not always correct for HR/HER status or molecular subtypes. Thus, the prognostic significance of TAMs in breast cancer should be reassessed in larger cohorts separately depending on molecular classifications. The majority of triple-negative cancers are of basal-like phenotype [21] which has the poorest prognosis. Basal-like breast cancer (BLBC) defined by Cheang et al. [22] was adopted in our study.

Macrophages exhibit striking plasticity and change their physiology according to environmental cues. This lead to heterogeneous populations of specific subsets with distinct phenotype, polarization and functions $[23,24]$. TAMs can be identified as two distinct states of polarized activation: the anti-tumor/pro-inflammatory M1 macrophages and the pro-tumoral/anti-inflammatory M2 macrophages $[25,26]$. M1 macrophages are characterized by expressing high levels of HLADR, inducible nitric oxide synthase (iNOS) and tumor necrosis factor- $\alpha$ (TNF-a), and by high microbicidal and tumoricidal activity, which are associated with a better prognosis [27]. In contrast, M2 macrophages typically express arginase 1 (ARG1), high levels of scavenging, mannose and galactose receptors, high levels of cytokines and chemokines that support their pro-tumoral functions [28]. M2 macrophages are involved in suppression of adaptive immunity, stimulation of angiogenesis, promotion of matrix remodeling and tumor invasion and migration.

In some cases, $\mathrm{CD}^{+} 8^{+}$TAMs were considered as a prognostic predictor in breast cancer. However, in some multivariate analyses, CD68 was not confirmed to be independent predictor of survival [14, 15, 17]. The most probable cause is both M1 and M2 macrophage can be stained by anti-CD68 Abs. CD163, the haemoglobin scavenger receptor, is typically expressed by TAMs and up-regulated in progressing neoplasms. In many studies, CD163 is regarded as a highly specific marker for M2-like polarized macrophages [29-32]. Some studies proved that $\mathrm{CD}_{163}{ }^{+}$TAMs was more closely related to unfavorable clinicopathological features in breast cancer [20]. However, to our knowledge no paper has reported the presence and prognostic significance of $\mathrm{CD}^{+}{ }^{+}$and $\mathrm{CD} 163^{+}$macrophages in the basal-like subset of breast cancer by molecular classification. Therefore, the aim of this study was to investigated the extent of infiltration and distribution patterns of macrophages in BLBC, to compare TAMs labeled by CD163 with those identified by the more frequently used pan-macrophage marker CD68, and to determine their association with clinicopathological features and prognostic value in BLBC.

\section{Materials and Methods}

\section{Patients}

We included 200 cases of BLBC from 1,971 contiguous cases of invasive breast cancer diagnosed at the Department of Pathology, Tianjin Medical University Cancer Hospital (Tianjin, China), between April 2006 and December 2007. Neoadjuvant therapy (NAT) will seriously affect the immune cells including TAMs in the tumor microenvironment, so all the patients selected in this study are BLBC patients who did not receive NAT before surgery. And we chose BLBCs that contain only IDC-NOS, which have relatively uniform molecular and pathological features (CONSORT diagram, Fig. 1). The patients were followed up for 12-86 months (median, 66 months), and the range of the patients age at the time of diagnosis was 26-81 years (median, 51 years). During the follow-up, $42(21 \%)$ patients died of cancer, and 66 patients (33\%) developed a breast cancer recurrence, included $9(4.5 \%)$ with local or regional tumor recurrence and 57 (28.5\%) with distant metastasis. All the patients underwent modified radical mastectomy or breast-conserving surgery with axillary lymph node dissection. Postoperatively, all the patients received adjuvant chemotherapy and 156 $(78 \%)$ received radiation therapy. All patients signed an informed consent form for the use of their biological tissues in the study. The study was reviewed and approved by the Institutional Ethics Committee of Tianjin Medical University Cancer Institute and Hospital, Tianjin, China (No. bc2015005). 
Contiguous cases of invasive breast cancer (IBC) with follow-up information ( $n=1971)$

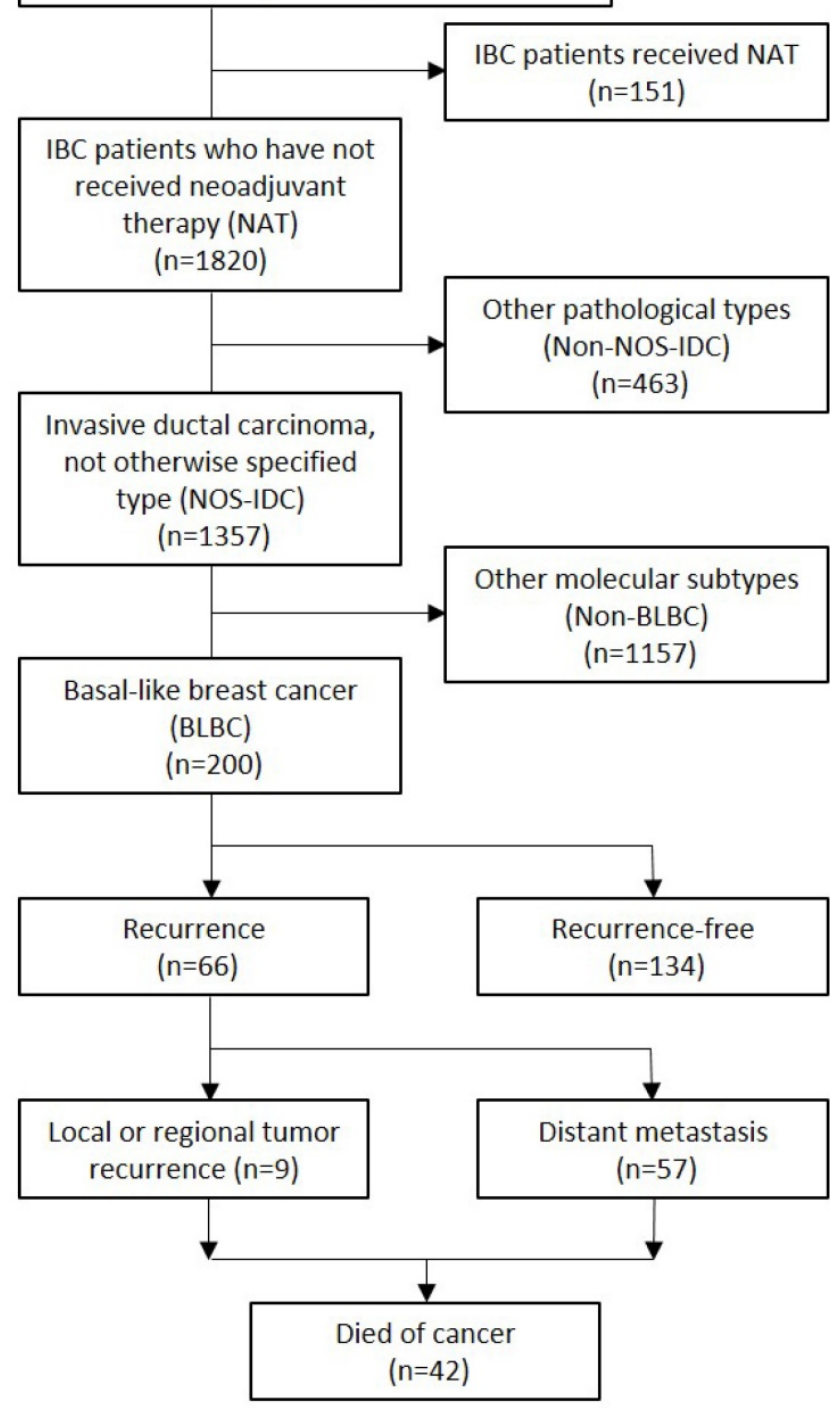

Fig. 1. CONSORT diagram.

\section{Immunohistochemistry}

Formalin-fixed, paraffin-embedded serial tissue sections of full block-face tissue from surgical specimen of each case were selected for $\mathrm{CD}^{+} 8^{+}$and $\mathrm{CD}_{163}{ }^{+}$immunohistochemical stains using standard procedures. Briefly, $4 \mu \mathrm{m}$ tissue sections were subsequently dewaxed and rehydrated using xylene and graded alcohol washes. Antigen retrieval was performed at $121^{\circ} \mathrm{C}$ for 2 min, using citrate buffer, $\mathrm{pH}$ 6.0. After serial blocking with hydrogen peroxide and normal goat serum, the sections were incubated with primary polyclonal antibody against CD68 (Abcam, ab213096, monoclonal [KP1], 0.5 $\mathrm{g} / \mathrm{ml})$ and CD163 (Abcam, ab74604, monoclonal [10D6]) for $30 \mathrm{~min}$ at room temperature. Then, the sections were sequentially incubated with biotinylated goat anti-mouse immunoglobulin and peroxidaseconjugated streptavidin.

TAMs were scored as the infiltration density of $\mathrm{CD}^{+} 8^{+}$or $\mathrm{CD} 163^{+}$cells with a monocyte/macrophage morphology with oval or rounded nuclei that showed strong membranous or cytoplasmic staining. In this study, TAMs in tumor nest (TN) is defined as the intraepithelial tumor-infiltrating macrophages. The definition of 'tumor stroma (TS)' in this study is the fibrous tissue surrounding tumor nest (Fig. 2); the lymphoid infiltrates surrounding the tumor bed are excluded. TAMs were evaluated by adapting the reported hotspot quantitative method.[17, 18, 33-36] The entire stained section was first scanned at low magnification $(\times 100)$ to identify the hotspot areas (five areas of TN and five areas of TS) with most abundant macrophages. The average count of macrophages in all five areas and the density of infiltration was estimated (per $0.24 \mathrm{~mm}^{2}$ ) at higher magnification $(\times 400)$. For statistical analyses, the density of CD163+ macrophages in the TS were dichotomized into low (0-36 macrophages $\left./ 0.24 \mathrm{~mm}^{2}\right)$ and high infiltration (>36 macrophages $/ 0.24 \mathrm{~mm}^{2}$ ) according to the median (Table 1). $\mathrm{CD}^{+} 8^{+}$macrophages in the TS were also scored by this critical value to unify the scoring criteria. Similarly, the density of CD163 in the TN was denoted as low (0-11 macrophages $\left./ 0.24 \mathrm{~mm}^{2}\right)$ and high ( $>11$ macrophages $/ 0.24 \mathrm{~mm}^{2}$ ) according to the median (Table 1), and the density of CD68 in the TN was also assessed by this critical value. Two researchers (pathologists) blinded to the clinical information carried out the evaluation process.

Additional immunohistochemistry was performed on serial tissue sections for molecular sub-classification of the tumors. Primary antibodies against ER (clone SP1, 1:150 dilution, Zymed, San Francisco, CA), PR (clone SP2, 1:150 dilution, Zymed), and HER2 (DAKO HercepTestTM, Denmark,), Ki-67 (clone SP6, 1:200 dilution, ThermoScientific, Fremont CA), EGFR (clone 31G7, 1:100 dilution, Zymed), and CK5/6 (clone D5/16B4, 1:100 dilution, Zymed) were applied according to manufacturer's instructions. Interpretation and scoring of ER, PR, HER2, Ki-67, EGFR, and CK5/ 6 staining described by Cheang et al. [22] was adopted in our study. Basal-like breast cancer was defined as ER negative, PR negative, HER2 negative, and EFGR and/or CK5/6 positive. Confirmatory fluorescence in situ hybridization (FISH) evaluation using Vysis kit (Vysis, Inc., Downers Grove, IL) was pursued on those tumors with a $2^{+}$HER 2 expression by immunohistochemistry. The interpretation was based up the manufacture guideline. 


\section{Statistical Analysis}

Spearman's Rho test was used to examine whether the expression levels of CD68 and CD163 in macrophages were associated with clinicopathological characteristics. Wilcoxon Signed Ranks Test was performed for comparing macrophages between different tissue locations. Overall survival (OS) was measured from the date of curative surgery to the date of breast cancer-specific death. Recurrence-free survival (RFS) was measured from the date of curative surgery to the date of breast cancer recurrence, regardless of whether recurrence was local or regional, and/or distant metastasis. Kaplan-Meier analysis and long-rank tests were performed to identify the difference in OS and RFS according to $\mathrm{CD}^{+} 8^{+}$and $\mathrm{CD} 163^{+}$macrophage infiltration. Cox regression proportional hazards models were performed to estimate the hazard ratios (HR) for RFS and OS of BLBC according to $\mathrm{CD}^{+} 8^{+}$and $\mathrm{CD}_{163^{+}}$macrophage infiltration in univariate and multivariate models. A two-sided $P<0.05$ was considered significant. Statistical analysis was performed with SPSS 19.0 software (SPSS, IBM).

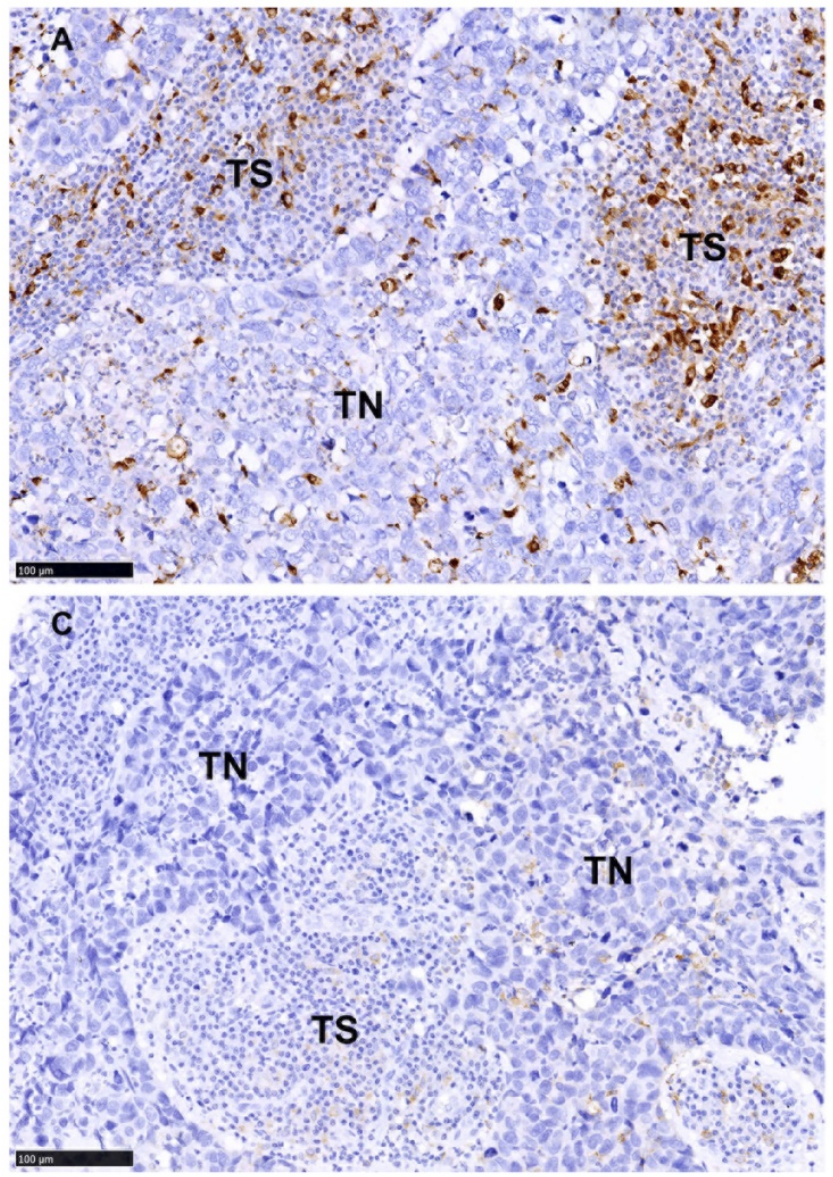

\section{Results}

\section{Characterization of $\mathrm{CD}^{2} 8^{+}$and $\mathrm{CD} 163^{+}$ macrophages in BLBC}

As shown in Fig. 2, CD68 ${ }^{+}$macrophages and $\mathrm{CD} 163^{+}$macrophages were present in both TS and TN of BLBC. We evaluated the macrophages in TS and TN separately and found significantly more macrophages infiltrated in TS than in TN (CD68: median 40 vs. 13; $Z=-11.725, p<0.001 ; C D 163$ : median 36 vs. $11 ; Z=-10.665, p<0.001$; Table 1 and Fig. 2$)$. The ratio of TN/total (CD68: median 0.24; CD163: median 0.24) and TS/Total (CD68: median 0.72; CD163: median 0.73 ) were also shown in Table 1 . There was a strong correlation between CD163 and CD68 in both TS $\left(r_{s}=0.404, p<0.001\right)$ and TN $\left(r_{s}=0.621, p<0.001\right)$. No correlation was identified between the infiltration density of $\mathrm{CD}_{163}{ }^{+}$macrophages in the TS and in the TN $\left(r_{s}=0.060, p=0.399\right)$ (Table 1$)$, while a significant correlation between the infiltration density of $\mathrm{CD} 68^{+}$ macrophages in the TS and in the TN $\left(r_{s}=0.275\right.$, $p<0.001$ ) (Table 1) was identified.
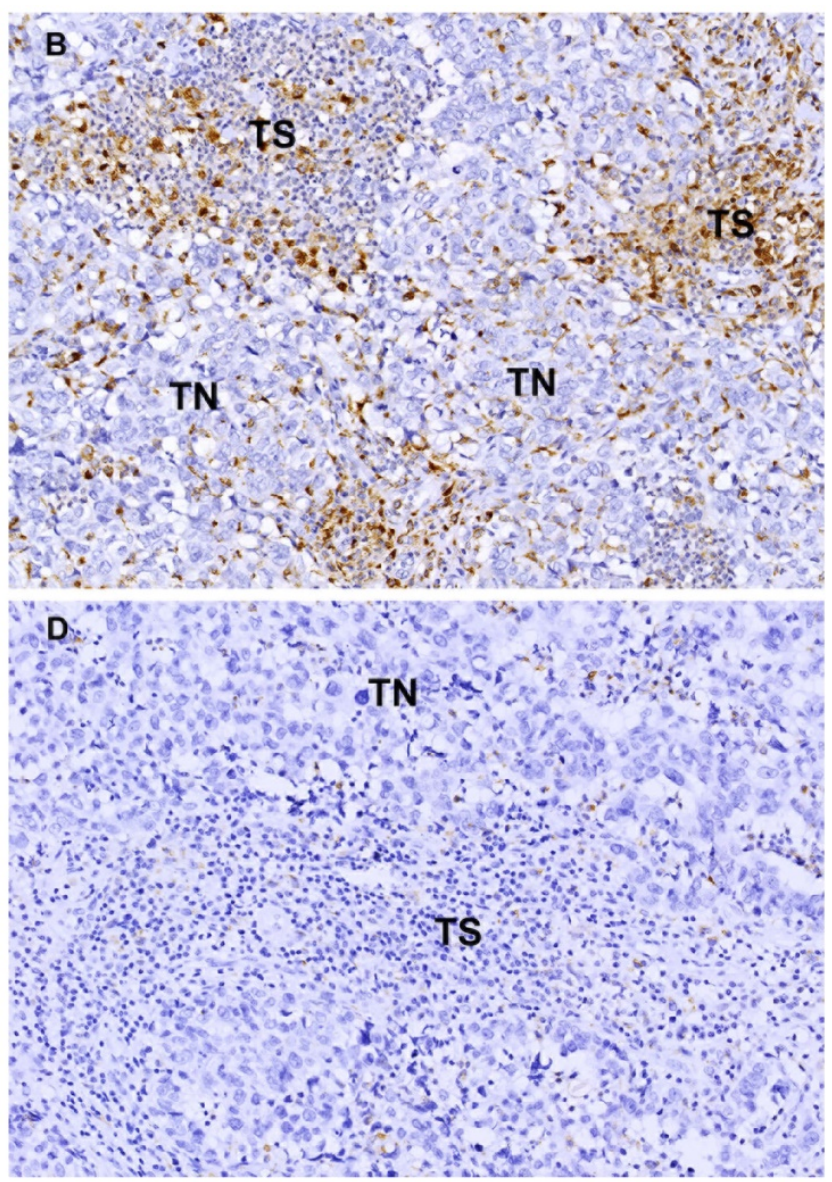

Fig. 2. The density and distribution pattern of macrophage infiltration characterized by CD68 and CD163 immunoreactivity in the tumor nest (TN) and tumor stroma (TS) of BLBC. A-B Representative images of high density of CD68+ staining (A) and CD163 staining (B) in TN and TS. C-D Representative images of low density of CD68+ staining (C) and CD163 staining (D) in TN and TS. Scale bar, $100 \mu \mathrm{m}$ 
Table 1. Distribution pattern of TAMs in BLBC

\begin{tabular}{|c|c|c|c|c|c|c|c|c|}
\hline Variables & Mean $^{\mathrm{a}}$ & SEa & Median $^{\mathrm{a}}$ & Range $^{a}$ & $Z^{\mathrm{b}}$ & $P^{\mathrm{b}}$ & $r_{s}^{c}$ & $P_{\mathrm{c}}$ \\
\hline $\mathrm{CD} 8^{+}$macrophage & & & & & -11.725 & $<0.001$ & 0.275 & $<0.001$ \\
\hline Tumor nest & 15 & 1.01 & 13 & $2-79$ & & & & \\
\hline Tumor stroma & 46 & 2.56 & 40 & $5-197$ & & & & \\
\hline $\begin{array}{l}\mathrm{CD} 163^{+} \\
\text {macrophage }\end{array}$ & & & & & -10.665 & $<0.001$ & 0.060 & 0.399 \\
\hline Tumor nest & 14 & 0.92 & 11 & $1-75$ & & & & \\
\hline Tumor stroma & 42 & 2.09 & 36 & $3-184$ & & & & \\
\hline \multicolumn{9}{|l|}{ TN/total } \\
\hline $\mathrm{CD} 8^{+}$macrophage & 0.23 & 0.01 & 0.24 & $0-0.63$ & & & & \\
\hline $\mathrm{CD} 163^{+}$macrophage & 0.25 & 0.01 & 0.24 & $0-0.61$ & & & & \\
\hline \multicolumn{9}{|l|}{ TS/Total } \\
\hline $\mathrm{CD} 8^{+}$macrophage & 0.72 & 0.01 & 0.72 & $0.38-1$ & & & & \\
\hline $\mathrm{CD} 163^{+}$macrophage & 0.74 & 0.01 & 0.73 & $0.35-0.94$ & & & & \\
\hline
\end{tabular}

\section{Correlations of CD68+ and CD163+ macrophages to clinicopathological features}

High infiltrations of $\mathrm{CD}^{+} 8^{+}$macrophage and $\mathrm{CD}_{163}{ }^{+}$macrophage in the TS were both positively associated with larger tumor size $\left(r_{s}=0.203, p=0.004\right.$; $r_{s}=0.284, p<0.001$, respectively), higher histological grade $\quad\left(r_{s}=0.153, \quad p=0.030 ; \quad r_{s}=0.581, \quad p<0.001\right.$, respectively), higher 5-year recurrence rate $\left(r_{s}=0.217\right.$, $p=0.002 ; r_{s}=0.145, p=0.041$, respectively) and higher 5 -year breast cancer mortality $\left(r_{s}=0.215, \quad p=0.002\right.$; $r_{s}=0.178, p=0.011$, respectively). Higher density of $\mathrm{CD} 63^{+}$macrophage $\left(r_{s}=-0.380, p<0.001\right)$, but not $\mathrm{CD}^{+} 8^{+}$macrophage $\left(r_{s}=-0.124, p=0.080\right)$, in the TS was observed in tumors of younger patients. There was no significant association between stromal $\mathrm{CD}^{+} 8^{+}$and $\mathrm{CD}_{163}{ }^{+}$macrophage infiltration and lymph node metastasis $\left(r_{s}=0.130, p=0.067 ; \quad r_{s}=0.029, p=0.688\right.$, respectively) (Table 2 and 3 ). In contrast, neither $\mathrm{CD}^{2} 8^{+}$macrophages nor $\mathrm{CD}_{163}{ }^{+}$macrophages in the TN was found significantly correlated with any of the above clinicopathological features $(p>0.05$; Table 2 and 3).

\section{Prognostic significance of $\mathrm{CD}^{6} 8^{+}$macrophages and $\mathrm{CD}_{163^{+}}$macrophages}

Univariate Cox proportional hazards regression analysis identified that the high density of $\mathrm{CD}^{+} 8^{+}$and $\mathrm{CD} 63^{+}$macrophage infiltration in TS was associated with poor OS $(\mathrm{HR}=2.985, p=0.005 ; \mathrm{HR}=3.548, p<0.001)$ and RFS (HR=2.229, $p=0.005 ; \mathrm{HR}=3.975, p<0.001)$ (Table 4; Fig. 3). In contrast, there was no correlation between $\mathrm{CD}^{2} 8^{+}$or $\mathrm{CD} 163^{+}$macrophages in TN with OS (HR=0.951, $p=0.870 ; \mathrm{HR}=1.322, p=0.371)$ and RFS $(\mathrm{HR}=0.925, p=0.753 ; \mathrm{HR}=1.496, p=0.108)$ (Table 4; Fig. $3)$.

Multivariate Cox proportional hazards regression analysis, after adjusting for patient age, tumor size, histological grade, lymph node stage and radiotherapy, proved $\mathrm{CD} 163^{+}$macrophages in TS, but not $\mathrm{CD}^{+} 8^{+}$macrophages, was an independent prognostic factor for worse OS (HR=3.427, $p=0.009$ ) and RFS $(\mathrm{HR}=4.304, p<0.001)$ (Table 5).

Table 2. Correlations between $\mathrm{CD}^{+} 8^{+}$macrophages and clinicopathological features in BLBC by their locations

\begin{tabular}{|c|c|c|c|c|c|c|c|}
\hline & & CD68 in & & & CD68 in & & \\
\hline Variables & $\mathrm{N}$ & $\begin{array}{l}\text { High, } \mathrm{n} \\
(\%)\end{array}$ & $r_{\mathrm{s}}$ & $P$ & $\begin{array}{l}\text { High, } \mathrm{n} \\
(\%)\end{array}$ & $r_{s}$ & $P$ \\
\hline Age, years & & & -0.124 & 0.080 & & -0.061 & 0.388 \\
\hline$<50$ & 98 & $62(63.3)$ & & & $55(56.1)$ & & \\
\hline$\geq 50$ & 102 & $52(51.0)$ & & & $51(50.0)$ & & \\
\hline Tumor size, $\mathrm{cm}$ & & & 0.203 & 0.004 & & 0.061 & 0.389 \\
\hline$\leq 2$ & 60 & $25(41.7)$ & & & $29(48.3)$ & & \\
\hline$>2$ & 140 & $89(63.6)$ & & & $77(55.0)$ & & \\
\hline $\begin{array}{l}\text { Histological Grade } \\
\text { (SBR) }\end{array}$ & & & 0.153 & 0.030 & & 0.037 & 0.608 \\
\hline Grade 1 & 0 & 0 & & & 0 & & \\
\hline Grade 2 & 94 & $46(48.9)$ & & & $48(51.1)$ & & \\
\hline Grade 3 & 106 & $68(64.2)$ & & & $58(54.7)$ & & \\
\hline Lymph node metastasis & & & 0.130 & 0.067 & & 0.002 & 0.978 \\
\hline Negative & 123 & $63(51.2)$ & & & $67(54.5)$ & & \\
\hline 1 to 3 & 43 & $30(69.8)$ & & & 19(44.2) & & \\
\hline 4 to 9 & 22 & $14(63.6)$ & & & $8(36.4)$ & & \\
\hline 10 or more & 12 & $7(58.3)$ & & & $12(100)$ & & \\
\hline Recurrence (5 years) & & & 0.217 & 0.002 & & 0.041 & 0.568 \\
\hline No & 156 & $80(51.3)$ & & & $81(51.9)$ & & \\
\hline Yes & 44 & $34(77.3)$ & & & $25(56.8)$ & & \\
\hline $\begin{array}{l}\text { Breast cancer mortality } \\
\text { ( } 5 \text { years) }\end{array}$ & & & 0.215 & 0.002 & & 0.022 & 0.758 \\
\hline No & 162 & $84(51.9)$ & & & $85(52.5)$ & & \\
\hline Yes & 38 & $30(78.9)$ & & & 21(55.3) & & \\
\hline
\end{tabular}

TS, tumor stroma; TN, tumor nest; BLBC, basal-like breast cancer.

Table 3. Correlations between $\mathrm{CD} 63^{+}$macrophages and clinicopathological features in BLBC by their locations

\begin{tabular}{|c|c|c|c|c|c|c|c|}
\hline & & CD163 i & & & CD163 i & & \\
\hline Variables & $\mathrm{N}$ & $\begin{array}{l}\text { High, } \mathrm{n} \\
(\%)\end{array}$ & $r_{s}$ & $P$ & $\begin{array}{l}\text { High, } \mathrm{n} \\
(\%)\end{array}$ & $r_{s}$ & $P$ \\
\hline Age, years & & & -0.380 & $<0.001$ & & -0.100 & 0.159 \\
\hline$<50$ & 98 & $68(69.4)$ & & & $54(55.1)$ & & \\
\hline$\geq 50$ & 102 & $32(31.4)$ & & & $46(45.1)$ & & \\
\hline Tumor size, cm & & & 0.284 & $<0.001$ & & 0.022 & 0.759 \\
\hline$\leq 2$ & 60 & $17(28.3)$ & & & $29(48.3)$ & & \\
\hline$>2$ & 140 & $83(59.3)$ & & & $71(50.7)$ & & \\
\hline $\begin{array}{l}\text { Histological Grade } \\
\text { (SBR) }\end{array}$ & & & 0.581 & $<0.001$ & & -0.020 & 0.778 \\
\hline Grade 1 & 0 & 0 & & & 0 & & \\
\hline Grade 2 & 94 & 18(19.1) & & & $48(51.1)$ & & \\
\hline Grade 3 & 106 & $82(77.4)$ & & & $52(49.1)$ & & \\
\hline Lymph node metastasis & & & 0.029 & 0.688 & & 0.011 & 0.872 \\
\hline Negative & 123 & $58(47.2)$ & & & $62(50.4)$ & & \\
\hline 1 to 3 & 43 & $29(67.4)$ & & & $19(44.2)$ & & \\
\hline 4to 9 & 22 & $8(36.4)$ & & & $11(50.0)$ & & \\
\hline 10 or more & 12 & $5(41.7)$ & & & $8(66.7)$ & & \\
\hline Recurrence (5 years) & & & 0.145 & 0.041 & & 0.072 & 0.308 \\
\hline No & 156 & $72(46.2)$ & & & $75(48.1)$ & & \\
\hline Yes & 44 & $28(63.6)$ & & & $25(56.8)$ & & \\
\hline $\begin{array}{l}\text { Breast cancer mortality } \\
\text { ( } 5 \text { years) }\end{array}$ & & & 0.178 & 0.011 & & 0.051 & 0.473 \\
\hline No & 162 & $74(45.7)$ & & & $79(48.8)$ & & \\
\hline Yes & 38 & $26(68.4)$ & & & $21(55.3)$ & & \\
\hline
\end{tabular}

TS, tumor stroma; TN, tumor nest; BLBC, basal-like breast cancer. 

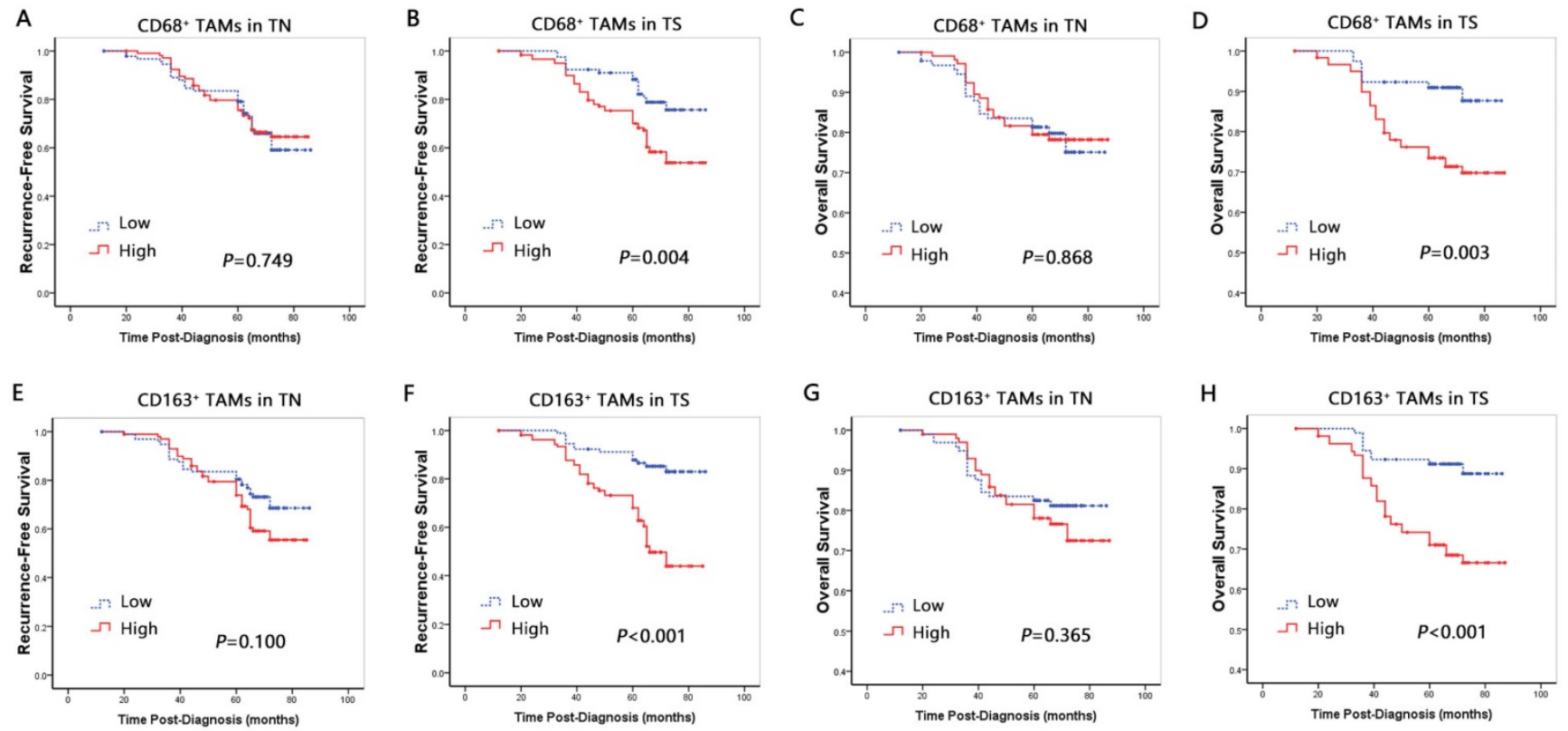

Fig. 3. RFS and OS curves based on macrophage properties. A-D Recurrence-free survival and Overall survival curves by CD68-positive macrophage infiltration into the tumor nest $(\mathbf{A}, \mathbf{C})$ and stroma (B, D). E-H Overall survival curves by CD163-positive M2 macrophage infiltration into the tumor nest (E, G) and stroma (F, H).

Table 4. Univariate Cox regression analyses for RFS and OS of BLBC

\begin{tabular}{|c|c|c|c|c|c|c|}
\hline Variables & OS & & & RFS & & \\
\hline & HR & $95 \% \mathrm{CI}$ & $P$ & HR & $95 \% \mathrm{CI}$ & $P$ \\
\hline Age $(<50$ vs. $\geq 50)$ & 1.937 & $0.277-0.973$ & 0.038 & 1.472 & $0.401-1.149$ & 0.150 \\
\hline Tumor size, $\mathrm{cm}(\leq 2$ vs. $>2)$ & 4.999 & $1.782-14.023$ & 0.002 & 4.314 & $2.055-9.054$ & $<0.001$ \\
\hline $\begin{array}{l}\text { Histological Grade (II } v s \text {. } \\
\text { III) }\end{array}$ & 1.105 & $0.599-2.040$ & 0.749 & 1.235 & $0.753-2.026$ & 0.402 \\
\hline $\begin{array}{l}\text { Lymph node stage (N0 vs. } \\
\text { N1-3) }\end{array}$ & 1.932 & $1.490-2.504$ & $<0.001$ & 1.929 & $1.573-2.366$ & $<0.001$ \\
\hline Radiotherapy (no $v s$. yes) & 3.606 & $2.043-6.364$ & $<0.001$ & 5.755 & $3.217-10.294$ & 0.000 \\
\hline $\mathrm{CD68}^{+}$in TS (low vs. high) & 2.985 & $1.381-6.449$ & 0.005 & 2.229 & $1.269-3.914$ & 0.005 \\
\hline $\begin{array}{l}\text { CD163+ in TS (low vs. } \\
\text { high) }\end{array}$ & 3.548 & $1.697-7.417$ & $<0.001$ & 3.975 & $2.200-7.180$ & $<0.001$ \\
\hline $\mathrm{CD68}^{+}$in TN (low vs. high) & 0.951 & $0.519-1.742$ & 0.870 & 0.925 & $0.571-1.500$ & 0.753 \\
\hline $\begin{array}{l}\text { CD163+ in TN (low vs. } \\
\text { high) }\end{array}$ & 1.322 & $0.717-2.436$ & 0.371 & 1.496 & $0.916-2.445$ & 0.108 \\
\hline
\end{tabular}

Table 5. Multivariate Cox regression analyses for RFS and OS of BLBC

\begin{tabular}{|c|c|c|c|c|c|c|}
\hline Variables & OS & & & RFS & & \\
\hline & HR & $95 \% \mathrm{CI}$ & $P$ & HR & $95 \% \mathrm{CI}$ & $P$ \\
\hline Age $(<50$ vs. $\geq 50)$ & 2.463 & $0.184-0.897$ & 0.026 & 2.032 & $0.244-0.991$ & 0.047 \\
\hline Tumor size, $\mathrm{cm}(\leq 2$ vs. $>2)$ & 3.020 & $1.030-8.854$ & 0.044 & 2.581 & $1.192-5.588$ & 0.016 \\
\hline Histological Grade (II vs. III) & 1.435 & $0.647-3.180$ & 0.374 & 1.367 & $0.722-2.588$ & 0.338 \\
\hline $\begin{array}{l}\text { Lymph node stage (N0 vs. } \\
\text { N1-3) }\end{array}$ & 1.748 & $1.311-2.331$ & $<0.001$ & 1.836 & $1.468-2.297$ & $<0.001$ \\
\hline Radiotherapy (no vs. yes) & 1.328 & $0.938-1.882$ & 0.110 & 1.190 & $0.906-1.564$ & 0.212 \\
\hline $\mathrm{CD}^{+} 8^{+}$in TS (low vs. high) & 1.850 & $0.796-4.298$ & 0.153 & 1.250 & $0.666-2.345$ & 0.487 \\
\hline $\mathrm{CD}{ }^{+}{ }^{+}$in TS (low vs. high) & 3.427 & $1.368-8.587$ & 0.009 & 4.304 & $1.994-9.286$ & $<0.001$ \\
\hline
\end{tabular}

\section{Discussion}

Macrophages are heterogeneous subsets with different functions. CD68 has been used to recognize tumoricidal M1 and pro-tumoral M2 macrophages. Even though multiple clinical studies had evidenced that $\mathrm{CD} 68^{+}$macrophage positively associated with high vascularity and nodal metastasis and negatively correlated with RFS and OS in breast cancer, as a pan-macrophage marker, CD68 was found not an independent predictor of OS in some multivariate analyses [14, 15, 17]. A prior study using tissue microarrays (TMAs) with a large sample size suggests that overall numbers of $\mathrm{CD}^{+} 8^{+}$macrophages are not related to prognosis in breast cancer [15]. These results demand further investigation to identify the subset of TAMs that may service as the prognosis-related biomarkers. Meanwhile, CD163, a highly specific biomarker for M2 macrophages [29, 32], was found to be closely correlated with unfavorable clinicopathological characters in some study.[20] It has been recently found that BLBC hosts more TAMs infiltration, particularly the $\mathrm{CD} 163^{+}$cells, than other types of breast cancers [20]. However, the study with a small number of BLBC cases did not explore the prognostic significance of $\mathrm{CD}^{+} 8^{+}$and $\mathrm{CD}_{163}{ }^{+}$macrophages in BLBC. We therefore undertook the study to evaluate the infiltration of stromal and intraepithelial $\mathrm{CD} 68^{+}$macrophages along with the identification of $\mathrm{CD}_{163}{ }^{+}$macrophages to assess their prognostic value in a larger BLBC cohort. In addition, TAMs in different intratumoral regions are subsets with distinct molecular and functional features, and thus may exhibit different prognostic values. Unfortunately, limited studies have considered the locations in the evaluation of clinical significance. Although three studies (two by marker of CD68 [15, 33] and one by markers of CD68 and CD163 [20]) in human breast cancer have included the locations of TAMs, two of which used the TMA 
samples to put it into practice $[15,20]$. We used full block-face tissue sections in the study to overcome the limitation of core materials that only contain small volume of tumor tissue may suffer from bias in the assessment of TAMs due to tumor heterogeneity. Full block-face tissue sections allow the selection of tumor areas with abundant TAMs for accurate scoring in tumor nest and in tumor stroma separately.

In this cohort of $\mathrm{BLBC}, \mathrm{CD}^{+} 8^{+}$or $\mathrm{CD} 163^{+}$ macrophages in TN was not found to be correlated with any of the clinicopathological features, OS or RFS. Medrek et al. recently also found no correlations between clinicopathological features and $\mathrm{CD}^{+} 8^{+}$or $\mathrm{CD}_{163}{ }^{+}$macrophage infiltrates in tumor nest, and the same relationship with RFS and OS was also noted [20]. Mahmoud et al. reported that intratumoural $\mathrm{CD}^{+} 8^{+}$macrophage did not correlate with breast cancer-specific survival [15]. Although the methods and molecular subtypes of breast cancer patients were different in these studies, the results suggest that the TAMs infiltrates into tumor nest is not an important prognostic factor for patient outcome.

TAM promotes tumor progression through several mechanisms [37]. In contrast to TN, the study found that increased $\mathrm{CD} 68^{+}$or $\mathrm{CD} 163^{+}$macrophages in TS were correlated with larger tumor size, higher histological grade, and worse RFS and OS. It suggested that TAMs may affect the prognosis of BLBC mainly through modulating the immune response by contacting with tumor-infiltrating lymphocytes in TS, rather than through the direct interaction between macrophages and cancer cells in $\mathrm{TN}$, such as phagocytosis of cancer cells. However, the specific underlying mechanisms need further study. It is worthy of notice that although univariate analysis identified the total TAM infiltrates in TS was associated with poor RFS and OS in BLBC, multivariate analysis only proved $\mathrm{CD} 163^{+}$ macrophages in TS was an independent predictor of RFS and OS. We also got similar conclusions in multivariate Cox regression analyses using continuous variables, one-quarter and median as the cutoffs, i.e., $\mathrm{CD}_{163^{+}}$macrophages in TS was an independent prognostic factor for worse OS and RFS (Supplementary Table 1). It indicates that in contrast to the pan-macrophage marker CD68, macrophages expressing the anti-inflammatory CD163 marker (M2 macrophages) are probably the effect TAMs that facilitate the poor prognosis of BLBC and serve as an independent prognostic predictor.

A number of potential macrophage-centred therapeutic strategies are being explored [37]. Either manipulating TAMs localization at tumor sites, or targeting the signal pathways affecting TAMs polarization and functions is proved to improve the outcomes of breast cancer [38]. The pro-tumor M2 macrophage, recognized by CD163, is reversible [39, 40]. Duluc et al. used INF- $\gamma$ to reverse the immunosuppressive and pro-tumoral foundations and prevent the generation of M2 macrophage [41]. Similar to the result, Guiducci et al. activated TLR9 by its ligand $\mathrm{CpG}$, along with antibody to IL-10, and switched TAMs from an M2 macrophage to an M1 macrophage [42]. And classically activated M1 macrophage can kill cancer cells and induce tumor-destructive reaction [43]. Therefore, blocking key molecular determinants of macrophage polarization may result in reorientation of macrophage polarization and activate the anti-tumor activity [39, 44, 45]. In a preclinical glioma model, a small molecule agent BZL945 (CSF-1R inhibitor) improved the survival by 're-education' of macrophages from a protumor M2-like phenotype to an antitumor M1-like type instead of TAM number depletion [46]. Although TAM-centered strategies have not been yet introduced in clinical practice in terms of effectiveness and tolerability in breast cancer patients, reducing number or reeducating of TAM seems to be a promising strategy and should be further investigated due to its clinical significance in BLBC.

There are limitations in the study. Although CD163 was regarded as a highly special M2 macrophage marker, it can also be expressed by monocytederived dendritic cells (MDCs) [47]. Medrek C et al. observed some $\mathrm{CD} 163^{+}$areas lacked CD68 expression. They attributed this to a CD163-expressing subset of immature myeloid derived suppressor cells with prognostic impact although no direct data was available [20]. Thus, we cannot exclude MDCs cells or myeloid derived cells expressing CD163, which could have impact on the poor prognosis trigged by CD163+ macrophage in BLBC. It is warranting to further clarify the phenotype of TAMs and the significant impact of M1/M2 macrophage ratio on the clinical course of BLBC patients. Few specific markers are so far available, and therefore there is still an urgent need to identify markers specific for M1/M2 macrophage. Some other TAM-related biomarkers that have been explored include CD206, VEGF, HIFs, TFL, PCNA and CCL18 [4]. Further investigation to identify their roles in sub-classifying TAMs into different prognosis-related biological groups will be meaningful and will be one of the focuses of our future studies.

\section{Conclusion}

This study identified that infiltration of $\mathrm{CD}^{+} 8^{+}$or $\mathrm{CD}_{163}{ }^{+}$macrophages in TS, not the TN, is associated with the clinicopathological features of BLBC and 
worse prognosis of patients. $\mathrm{CD} 163^{+}$macrophages in TS, instead of $\mathrm{CD}^{+} 8^{+}$macrophage, is proven to an independent risk factor for worse RFS and OS. TAMs signature is a promising therapeutic target in BLBC. However, further work is still warranting to validate the findings.

\section{Acknowledgments}

Research supported by grants from the National Natural Science Foundation of China (Grant No. 81202101 and 31400673) and Natural Science Foundation of Tianjin City (Grant No. 15JCQNJC45 300).

\section{Supplementary Material}

Supplementary table.

http://www.jcancer.org/v09p2308s1.pdf

\section{Competing Interests}

The authors have declared that no competing interest exists.

\section{References}

1. Mantovani A, Allavena P, Sica A, Balkwill F. Cancer-related inflammation. Nature. 2008; 454: 436-44.

2. Coussens LM, Zitvogel L, Palucka AK. Neutralizing tumor-promoting chronic inflammation: a magic bullet? Science. 2013; 339: 286-91.

3. Pollard JW. Macrophages define the invasive microenvironment in breast cancer. Journal of Leukocyte Biology. 2008; 84: 623-30.

4. Tang X. Tumor-associated macrophages as potential diagnostic and prognostic biomarkers in breast cancer. Cancer letters. 2013; 332: 3-10.

5. Bingle L, Brown NJ, Lewis CE. The role of tumour-associated macrophages in tumour progression: implications for new anticancer therapies. J Pathol. 2002; 196: 254-65.

6. Mantovani A, Sozzani S, Locati M, Allavena P, Sica A. Macrophage polarization: tumor-associated macrophages as a paradigm for polarized M2 mononuclear phagocytes. Trends Immunol. 2002; 23: 549-55.

7. Pollard JW. Tumour-educated macrophages promote tumour progression and metastasis. Nat Rev Cancer. 2004; 4: 71-8.

8. Perez EA. Breast Cancer Management: Opportunities and Barriers to an Individualized Approach. The Oncologist. 2011; 16: 20-2.

9. den Hollander P, Savage MI, Brown PH. Targeted therapy for breast cancer prevention. Front Oncol. 2013; 3: 250.

10. Gucalp A, Traina TA. Triple-negative breast cancer: adjuvant therapeutic options. Chemother Res Pract. 2011; 2011: 696208.

11. Volodko N, Reiner A, Rudas M, Jakesz R. Tumour-associated macrophages in breast cancer and their prognostic correlations. The Breast. 1998; 7: 99-105.

12. Campbell MJ, Tonlaar NY, Garwood ER, Huo D, Moore DH, Khramtsov AI, et al. Proliferating macrophages associated with high grade, hormone receptor negative breast cancer and poor clinical outcome. Breast cancer research and treatment. 2011; 128: 703-11.

13. Chen J, Yao Y, Gong C, Yu F, Su S, Chen J, et al. CCL18 from tumor-associated macrophages promotes breast cancer metastasis via PITPNM3. Cancer cell. 2011; 19: 541-55.

14. Jubb AM, Soilleux EJ, Turley H, Steers G, Parker A, Low I, et al. Expression of vascular notch ligand delta-like 4 and inflammatory markers in breast cancer. The American journal of pathology. 2010; 176: 2019-28.

15. Mahmoud SM, Lee AH, Paish EC, Macmillan RD, Ellis IO, Green AR. Tumour-infiltrating macrophages and clinical outcome in breast cancer. Journal of clinical pathology. 2012; 65: 159-63.

16. Mukhtar RA, Moore AP, Nseyo O, Baehner FL, Au A, Moore DH, et al. Elevated PCNA+ tumor-associated macrophages in breast cancer are associated with early recurrence and non-Caucasian ethnicity. Breast cancer research and treatment. 2011; 130: 635-44.

17. Tsutsui S, Yasuda K, Suzuki K, Tahara K, Higashi H, Era S. Macrophage infiltration and its prognostic implications in breast cancer: the relationship with VEGF expression and microvessel density. Oncology reports. 2005; 14: 425-31.

18. Vicioso L, Gonzalez FJ, Alvarez M, Ribelles N, Molina M, Marquez A, et al. Elevated serum levels of vascular endothelial growth factor are associated with tumor-associated macrophages in primary breast cancer. American journal of clinical pathology. 2006; 125: 111-8.
19. Murri AM, Hilmy M, Bell J, Wilson C, McNicol AM, Lannigan A, et al. The relationship between the systemic inflammatory response, tumour proliferative activity, T-lymphocytic and macrophage infiltration, microvessel density and survival in patients with primary operable breast cancer. British journal of cancer. 2008; 99: 1013-9.

20. Medrek C, Ponten F, Jirstrom K, Leandersson K. The presence of tumor associated macrophages in tumor stroma as a prognostic marker for breast cancer patients. BMC cancer. 2012; 12: 306.

21. Badve S, Dabbs DJ, Schnitt SJ, Baehner FL, Decker T, Eusebi V, et al. Basal-like and triple-negative breast cancers: a critical review with an emphasis on the implications for pathologists and oncologists. Modern pathology: an official journal of the United States and Canadian Academy of Pathology, Inc. 2011; 24: 157-67.

22. Cheang MC, Voduc D, Bajdik C, Leung S, McKinney S, Chia SK, et al. Basal-like breast cancer defined by five biomarkers has superior prognostic value than triple-negative phenotype. Clin Cancer Res. 2008; 14: 1368-76.

23. Oliver RT, Nethersell AB, Bottomley JM. Unexplained spontaneous regression and alpha-interferon as treatment for metastatic renal carcinoma. British journal of urology. 1989; 63: 128-31.

24. Vogelzang NJ, Priest ER, Borden L. Spontaneous regression of histologically proved pulmonary metastases from renal cell carcinoma: a case with 5-year followup. The Journal of urology. 1992; 148: 1247-8.

25. Mosser DM, Edwards JP. Exploring the full spectrum of macrophage activation. Nat Rev Immunol. 2008; 8: 958-69.

26. Biswas SK, Sica A, Lewis CE. Plasticity of macrophage function during tumor progression: regulation by distinct molecular mechanisms. J Immunol. 2008; 180: 2011-7.

27. Allavena P, Sica A, Solinas G, Porta C, Mantovani A. The inflammatory micro-environment in tumor progression: the role of tumor-associated macrophages. Critical reviews in oncology/hematology. 2008; 66: 1-9.

28. Solinas G, Germano G, Mantovani A, Allavena P. Tumor-associated macrophages (TAM) as major players of the cancer-related inflammation. J Leukoc Biol. 2009; 86: 1065-73.

29. Lau SK, Chu PG, Weiss LM. CD163: a specific marker of macrophages in paraffin-embedded tissue samples. American journal of clinical pathology. 2004; 122: 794-801

30. Nguyen TT, Schwartz EJ, West RB, Warnke RA, Arber DA, Natkunam Y. Expression of CD163 (hemoglobin scavenger receptor) in normal tissues, lymphomas, carcinomas, and sarcomas is largely restricted to the monocyte/macrophage lineage. The American journal of surgical pathology. 2005; 29: 617-24.

31. Ambarus CA, Krausz S, van Eijk M, Hamann J, Radstake TR, Reedquist KA, et al. Systematic validation of specific phenotypic markers for in vitro polarized human macrophages. Journal of immunological methods. 2012; 375: 196-206.

32. Holness CL, Simmons DL. Molecular cloning of CD68, a human macrophage marker related to lysosomal glycoproteins. Blood. 1993; 81: 1607-13.

33. Ch'ng ES, Tuan Sharif SE, Jaafar H. In human invasive breast ductal carcinoma, tumor stromal macrophages and tumor nest macrophages have distinct relationships with clinicopathological parameters and tumor angiogenesis. Virchows Archiv: an international journal of pathology. 2013; 462: 257-67.

34. Ueno T, Toi M, Saji H, Muta M, Bando H, Kuroi K, et al. Significance of macrophage chemoattractant protein-1 in macrophage recruitment, angiogenesis, and survival in human breast cancer. Clin Cancer Res. 2000; 6: 3282-9.

35. Saji H, Koike M, Yamori T, Saji S, Seiki M, Matsushima K, et al. Significant correlation of monocyte chemoattractant protein-1 expression with neovascularization and progression of breast carcinoma. Cancer. 2001; 92: 1085-91.

36. Tiainen S, Tumelius R, Rilla K, Hamalainen K, Tammi M, Tammi R, et al. High numbers of macrophages, especially M2-like (CD163-positive), correlate with hyaluronan accumulation and poor outcome in breast cancer. Histopathology. 2015; 66: 873-83.

37. Mantovani A, Marchesi F, Malesci A, Laghi L, Allavena P. Tumour-associated macrophages as treatment targets in oncology. Nature reviews Clinical oncology. 2017; 14: 399-416.

38. Tang X, Mo C, Wang Y, Wei D, Xiao H. Anti-tumour strategies aiming to target tumour-associated macrophages. Immunology. 2013; 138: 93-104.

39. Saccani A, Schioppa T, Porta C, Biswas SK, Nebuloni M, Vago L, et al. p50 nuclear factor-kappaB overexpression in tumor-associated macrophages inhibits M1 inflammatory responses and antitumor resistance. Cancer Res. 2006; 66: 11432-40.

40. Stout RD, Watkins SK, Suttles J. Functional plasticity of macrophages: in situ reprogramming of tumor-associated macrophages. Journal of leukocyte biology. 2009; 86: 1105-9.

41. Duluc D, Corvaisier M, Blanchard S, Catala L, Descamps P, Gamelin E, et al Interferon-gamma reverses the immunosuppressive and protumoral properties and prevents the generation of human tumor-associated macrophages. International journal of cancer Journal international du cancer. 2009; 125: 367-73.

42. Guiducci C, Vicari AP, Sangaletti S, Trinchieri G, Colombo MP. Redirecting in vivo elicited tumor infiltrating macrophages and dendritic cells towards tumor rejection. Cancer Res. 2005; 65: 3437-46.

43. Schmidt T, Carmeliet P. Blood-vessel formation: Bridges that guide and unite. Nature. 2010; 465: 697-9. 
44. Ostrand-Rosenberg S. Immune surveillance: a balance between protumor and antitumor immunity. Curr Opin Genet Dev. 2008; 18: 11-8.

45. Kortylewski M, Kujawski M, Wang T, Wei S, Zhang S, Pilon-Thomas S, et al. Inhibiting Stat 3 signaling in the hematopoietic system elicits multicomponent antitumor immunity. Nat Med. 2005; 11: 1314-21.

46. Pyonteck SM, Akkari L, Schuhmacher AJ, Bowman RL, Sevenich L, Quail DF, et al. CSF-1R inhibition alters macrophage polarization and blocks glioma progression. Nat Med. 2013; 19: 1264-72.

47. Maniecki MB, Moller HJ, Moestrup SK, Moller BK. CD163 positive subsets of blood dendritic cells: the scavenging macrophage receptors CD163 and CD91 are coexpressed on human dendritic cells and monocytes. Immunobiology. 2006; 211: 407-17. 